\title{
High-Pressure Homogenisation for Food Sanitisation
}

\author{
Donsì, F., ${ }^{1}$ Ferrari, G., ${ }^{1,2}$ Maresca, P. ${ }^{1}$ \\ ${ }^{1}$ Department of Chemical and Food Engineering, University of Salerno, Fisciano (SA), Italy \\ ${ }^{2}$ Centro Regionale di Competenza Produzioni Agroalimentari, Fisciano (SA), Italy \\ fdonsi@unisa.it
}

\begin{abstract}
The inactivation by high-pressure homogenisation of two microbial strains similar in shape but of different membrane resistance, namely a Gram-negative, Escherichia coli, and a Grampositive bacterium, Lactobacillus delbrueckii, was investigated to clarify the main factors influencing cell inactivation. Tests were carried in a lab-scale Stansted Power Fluid highpressure homogenizer up to $250 \mathrm{MPa}$ and several homogenization cycles. Results exhibited a strong dependence on initial cell concentration, which suggests a cell-cell interaction in the disruption valve enhancing bacterial inactivation to higher extent than in other homogenisation apparatus reported in literature. In addition, a strong difference was found between the two bacterial strains, with the Gram-positive one exhibiting a significantly higher resistance to the treatment.

Hence, a treatment was optimised for fruit juices, by determining the optimal operating pressure and number of passes through the homogeniser for achieving the lethal disruption of the bacteria, yet preserving the sensory and nutritional attributes.
\end{abstract}

\section{Introduction}

Application of high-pressure homogenisation

Liquid foodstuff may host high concentrations of microorganisms deriving from the raw material or from food processing. High-pressure homogenization (HPH) treatment is a mild technology of potential use in food sanitization, due to its capability of preserving the organoleptic and qualitative properties of the fresh product (Popper and Knorr, 1990). When the foodstuff undergoes HPH, the microbial cells experience a non-specific tearing apart of the cell wall determined by the physical interaction of the cells with the small-gap homogenisation valve (Middelberg, 1995).

Homogenisation has been extensively used by the dairy and food industry, especially to stabilize food emulsions and to disrupt lipid globules. The introduction of the high-pressure homogenisation opened up new areas of application for the dairy and food industry, permitting the production of finer emulsions, and the modification not only of lipid globules but also of food constituents (Paquin, 1999).

Recently, great interest also gathered the inactivation of pathogenic and other food spoilage microorganisms. Concerning the dairy industry, Guerzoni and coworkers deeply investigated the resistance of different microorganisms to homogenisation up to $100 \mathrm{MPa}$ in milk (Lanciotti et al., 1994 and 1996). In particular, the authors focused on the HPH treatment of milk for the production of yoghurt (Lanciotti et al., 2004b) and of cheese (Lanciotti et al., 2004a; Guerzoni et al., 1999; Lanciotti et al., 2006), highlighting that HPH had both direct and indirect effects on cheese characteristics and their evolution during ripening, in addition to a significant contribution to the non-thermal pasteurisation of the raw milk.

Similarly, Vachon and coworkers investigated the effect of HPH treatment of milk (up to $200 \mathrm{MPa}$ for five cycles) in the production of Cheddar cheese, showing a three to four logcycle reduction of $L$. innocua and reductions in size of casein micelles and fat globules (Kheadr et al., 2002).

The influence of homogenisation pressure (100-300 MPa), in conjunction with milk inlet temperature on fat globule size distribution and on the reduction of the endogenous flora were 
investigated by Cheftel and coworkers, with the results that increasing pressure and number of passes reduced the microorganims population, while fat globules decreased in size only up to $200 \mathrm{MPa}$. Higher pressures (around $300 \mathrm{MPa}$ ) induced the clustering of fat globules (Thiebaud et al., 2003).

Another field of potential interest is represented by fruit juices. A patent was issued to Coca Cola Company already in 1993 for the homogenisation under ultra-high pressure of citrus juices at about $100 \mathrm{MPa}$. The treated juices seemed to exhibit an increased shelf life (up to 40 days at $4^{\circ} \mathrm{C}$ ) and decreased microbiological activity despite the fact that no thermal pasteurization step was conducted (Clark et al., 1993).

Tahiri et al. (2006) studied the inactivation of pathogenic and spoilage microflora in orange juice. Their results revealed the potential of HPH to inactivate all the tested microorganisms and suggested that it could constitute a promising alternative technology for cold pasteurization of fruit juices.

Also our research group investigated the effect of multi-pass homogenisation up to $250 \mathrm{MPa}$ on orange, apple and ananas juices, evaluating the microbial inactivation and quality loss of the treated products. Interestingly, HPH appears effective in extending the shelf life of the fruit juice, maintaining fresh-like organoleptic attributes (Maresca et al., 2006).

\section{Mechanisms of cell disruption}

Notwithstanding the number of works on the subject, uncertainty exists in the literature about the exact cause of cell disruption in high-pressure homogenisers. Numerous physical phenomena have been proposed, including cavitation, turbulence, impingement, shear and extensional stresses, and homogenisation pressure, which are controlled at different extent by product parameters (e.g. viscosity), operating parameters (e.g. volume flow rate, temperature) and device parameters (e.g. valve geometry).

Recently, some fundamental studies aimed at clarifying the influence of such physical factors. Experimental evidence was reported that Gram-negative bacteria are more sensitive to highpressure homogenisation than Gram-positive bacteria (Wuytack et al., 2002; Vachon et al., 2002), suggesting a correlation between cell wall structure and high-pressure resistance, which indicates that high-pressure homogenisation kills vegetative bacteria mainly through mechanical destruction of the cell integrity. Cells are indeed disrupted by high-pressure homogenisation without causing any sublethal injury (Vachon et al., 2002).

At the macroscopical level, microbial inactivation is affected mainly by fluid viscosity and temperature (Diels et al., 2004). Temperature effects have to be necessarily taken into account in HPH, since, upon homogenisation, an important rise of the temperature is observed in fluid downstream of the valve; nevertheless it was demonstrated that in the range between 0 and $45^{\circ} \mathrm{C}$, where it is not directly responsible for microbial inactivation, the role played by temperature is significant (Diels et al., 2004). By adjusting a solution inoculated with E. coli with different concentrations of polyethylene glycol to have the same viscosity at different temperatures, it was shown that the temperature effect up to $35-45^{\circ} \mathrm{C}$ can be entirely explained in terms of its indirect effect on fluid viscosity (Diels et al., 2004 and 2005), which in turn influences the flow patterns in high-pressure homogenising valves and has an effect on cavitation and fluid turbulence, and hence can influence cell disruption (Diels et al., 2005).

The inverse correlation of viscosity to microbial inactivation indicates cavitation, turbulence, and impact pressure in viscous fluids as the main causes of cell inactivation (Diels et al., 2004).

Another factor influencing microbial inactivation by HPH is represented by valve geometry. Most of the above reported experiments were carried out by Emulsiflex (Diels et al., 2003, 2004 and 2005; Kheadr et al., 2002; Moroni et al., 2002; Tahiri et al., 2006; Vachon et al., 2002; Wuytack et al., 2002) or Niro-Soavi homogenisers (Guerzoni et al., 1999 and 2002; 
Lanciotti et al., 1994, 1996, 2004a, 2004b, 2006; Vannini et al., 2004) or APV Gaulin (Wong et al., 1997), all characterized by a narrow channel (gap) between the valve piston and seat, from which the fluid emerges as a radial jet that impinges on an impact ring. Reducing the gap space increases the inlet homogenizer pressure upstream of the valve.

The Stansted Fluid Power valve design is characterized instead by flow directions through the valve reversed with respect to the classical valve design: the fluid is fed axially under high pressure along the mobile part of the valve, and flows with high velocity through the radial narrow gap formed between the valve seat and the piston. The size of the gap and the resulting stream velocity and pressure of the liquid ahead of the valve depend on the force acting on the valve piston, which can be adjusted to regulate the homogenising intensity. Since the operating pressure is controlled by adjusting the gap between the valve and seat, and the Stansted valve technology is able to reach a very high pressure (350 MPa). Only few results are presently available for HPH for bacterial inactivation (Thiebaud et al., 2003; Maresca et al., 2006)

\section{Aim of the work}

From this survey of the main reported applications of HPH to liquid foodstuff it is evident that the potentiality of HPH in the food industry is still under evaluation.

In particular we focused our investigation on two main aspects, which deserve careful consideration. The first aspect is that the mechanisms of microorganism inactivation are not fully understood: only recently, the correlation of the microbial disruption with the physical properties of the suspension medium (Diels et al., 2005) contributed to clarify some aspects of the issue. Hence, our tests were aimed at comparing the disruption of two microbial strains, Escherichia coli and Lactobacillus delbrueckii, in a lab-scale Stansted high-pressure homogenizer. This choice was pursued in view of the possible contribution to the clarification of the mechanism of cell disruption. In particular, HPH of E. coli is widely studied especially for the recovery of intracellular material, but none of the numerous studies reported was conducted with a high-pressure homogenizer of design similar to Stansted apparatus. Instead, the comparative investigation with $L$. delbrueckii finds reason in the similar shape but different membrane resistance of the two microorganisms.

The second aspect considered in this work is that the field of investigation of HPH was mainly restricted to milk-based food matrices, where significant reductions of the microbial flora were observed (Thiebaud et al., 2003; Vannini et al., 2004; Diels et al., 2005). Nevertheless, also fruit juices represent an interesting perspective for HPH. A second aim of this work is hence the determination of an optimal treatment for fruit juices, determining operating pressure and homogenisation cycles suitable for achieving the lethal disruption of the endogenous flora but also for maintaining the organoleptic and qualitative properties of the fresh product.

\section{Experimental}

\section{Preparation of samples}

Escherichia coli was grown to stationary phase by inoculating a single colony in LB nutrient broth in an aerated incubator (Haeraeus Instruments) at $37^{\circ} \mathrm{C}$ for $24 \mathrm{~h}$. Lactobacillus delbrueckii was grown to stationary phase by inoculating a single colony in MRS nutrient broth in anaerobic conditions at $32^{\circ} \mathrm{C}$ for $48 \mathrm{~h}$.

Cultures were centrifuged at $5000 \mathrm{rpm}$ for $5 \mathrm{~min}$ and the pellets were resuspended to a concentration of desired concentration in sterile water. Samples were poured into the inlet funnel of the homogeniser and processed at the selected pressure levels. 
To avoid the modification of cell concentration by natural growth after processing, samples after treatment were stored at $4^{\circ} \mathrm{C}$ before the microbiological assay. Each experiment was replicated at least three times.

Table 1. Chemical-physical properties of Annurca apple juice measured at $25^{\circ} \mathrm{C}$

\begin{tabular}{|c|c|c|c|c|}
\hline Sample & pH & $\begin{array}{c}\text { Refraction } \\
\text { Index }\end{array}$ & ${ }^{\circ}$ Brix \% & Vitamin C \\
\hline Annurca apple juice & 3.46 & 1.3520 & 12.8 & $10.4 \mathrm{mg} / 100 \mathrm{ml}$ \\
\hline
\end{tabular}

Samples of Annurca apple juice were processed in a bench-top high pressure homogeniser. Previously juice samples were centrifuged at $8000 \mathrm{rpm}$ and $20^{\circ} \mathrm{C}$ for $15 \mathrm{~min}$ to obtain a clear juice as required for a correct use of the homogenising valve. The chemical-physical properties of the clear juice were measured at $25^{\circ} \mathrm{C}$ and listed in Table 1. Sample stored at $14^{\circ} \mathrm{C}$ were thawed at ambient temperature before the treatment.

\section{High-pressure Stansted homogeniser}

The apparatus for HPH experiments is a high-pressure bench-scale homogenizer (nm-GEN 7400 series apparatus by Stansted Power Fluids, UK). It consists of a low-pressure air pump connected to a high pressure intensifier for continuous pressurization of the process fluids up to $275 \mathrm{MPa}$. Upon pressurization, the fluid is fed to a high-pressure disruption valve. The flow through a micrometric gap causes the physical disruption of microbial species. A cooling system upstream of the intensifier and in correspondence to the disruption valve completes the equipment.

Inoculated samples were homogenised at varying pressure level between 50 and $250 \mathrm{MPa}$, with inlet temperatures between 2 and $30^{\circ} \mathrm{C}$. Since a temperature increase of around $2^{\circ} \mathrm{C} / \mathrm{MPa}$ was expected after a homogenising cycle, a cooling jacket at the same temperature of the inlet sample was used. Unprocessed and homogenised samples were plate-counted and analysed with a Nikon optical microscope.

Juice samples were processed in three homogenising cycles at a pressure level of $150 \mathrm{MPa}$ and an initial temperature of $25^{\circ} \mathrm{C}$. A temperature increase of $20-25^{\circ} \mathrm{C}$ was expected after a homogenising cycle. Therefore, after each cycle, juice sample were cooled at ambient temperature before being reprocessed. Fresh and processed samples were stored at $4^{\circ} \mathrm{C}$ for 4 weeks. Microbiological and chemical-physical analyses were carried out on stored samples at fixed storage times $(0,7,14,21,28$ days). The total microbial count was determined by plate count method on PCA (Plate Count Agar) slants at $32^{\circ} \mathrm{C}$ for $72 \mathrm{~h}$, and expressed in $\mathrm{cfu} / \mathrm{ml}$ (colony forming units per $\mathrm{ml}$ of sample). For each test the survival fraction, $\mathrm{S}=\mathrm{N} / \mathrm{N}_{0}$, and the level of inactivation, $\log (\mathrm{S})$ were evaluated. Variations of $\mathrm{pH},{ }^{\circ} \mathrm{Brix} \%$, colour and Vitamin $\mathrm{C}$ of apple juice were measured at ambient temperature during the storage of the samples.

\section{Results and discussion}

\section{Cell inactivation}

Escherichia coli was suspended in water at different concentration prior to processing in order to investigate the effect of the microbial concentration on the efficiency of disruption. Results reported in Figure 1 clearly show a dependence on the initial concentration of the strain, with higher reduction at higher concentration. The sample with $10^{8} \mathrm{cfu} / \mathrm{ml}$ initial concentration (dil 1 in Figure 1) upon HPH treatment is reduced of 2 log-cycles already at $50 \mathrm{MPa}$ and of about 7 log-cycles at $250 \mathrm{MPa}$. The effect of the treatment for the $10^{6} \mathrm{cfu} / \mathrm{ml}$ sample (dil $100 \mathrm{in}$ Figure 1) is lower, with a deactivation of slightly more than 1 log-cycle at $50 \mathrm{MPa}$ growing up to around 5 log-cycles at the highest pressure $(250 \mathrm{MPa})$. The sample with $10^{7} \mathrm{cfu} / \mathrm{ml}$ initial 
concentration (dil 10 in Figure 1) exhibits an intermediate behaviour, with around 6 logcycles of highest deactivation.

Remarkably, the comparison of these results with literature data suggests a strong influence of the homogenising valve geometry on the extent of disruption. Diels et al. (2005a) reported evidence that, using an Emulsiflex C5 homogenising apparatus, for and initial concentration of $E$. coli comprised between $10^{8}$ and $10^{5} \mathrm{cfu} / \mathrm{ml}$, no significant variation was observed in cell inactivation.

The authors explained this result in terms of the negligible variation of viscosity at changing cell concentration, since viscosity is reckoned as the main parameter regulating cell disruption.

In contrast, Vachon et al. (2002), with the same Emulsiflex C5 homogeniser, previously reported that the efficacy of treatment of Escherichia coli (in PBS and raw milk) was indeed dependent on initial cell concentration, with the highest reduction obtained when the bacterial load did not exceed $10^{5} \mathrm{cfu} / \mathrm{ml}$.

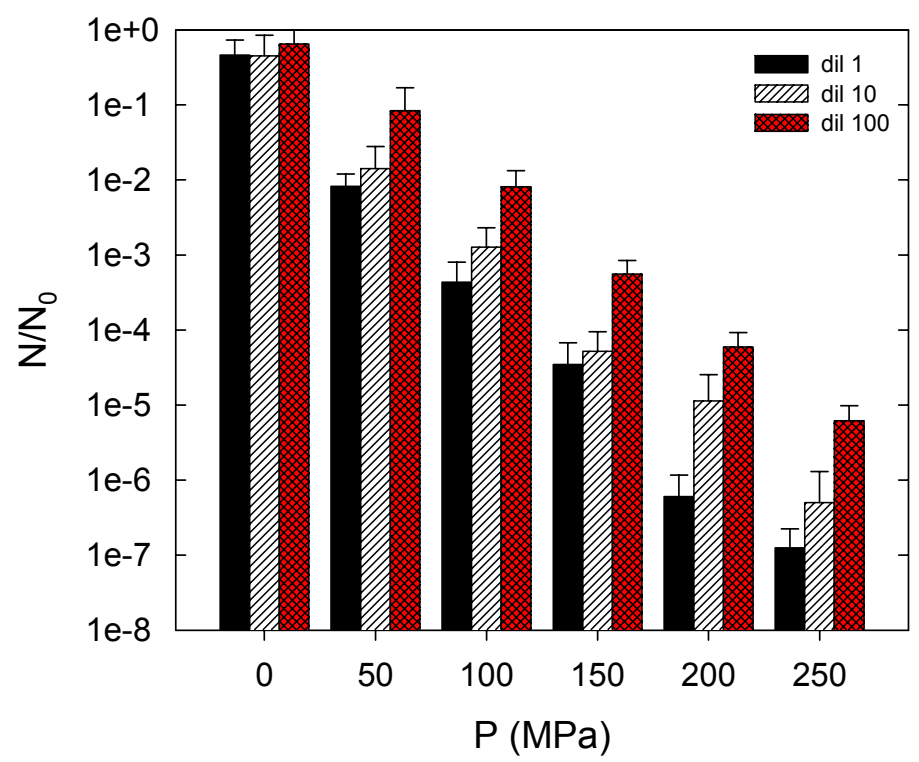

Figure 1. E. coli inactivation upon HPH at different initial concentrations (dil $1=10^{8} \mathrm{cfu} / \mathrm{ml}$; dil $10=10^{7} \mathrm{cfu} / \mathrm{ml}$; dil $100=10^{6} \mathrm{cfu} / \mathrm{ml}$ ) and $2^{\circ} \mathrm{C}$ inlet temperature.

Viscosity measurements conducted on the samples confirmed the findings that viscosity is relatively unaffected by increasing cell concentration at least up to $10^{8} \mathrm{cfu} / \mathrm{ml}$. Hence, the differences in inactivation can not be attributed to viscosity variations, but can be reasonably ascribed to a cell-cell interaction, which becomes an important factor in the Stansted homogenizing valve and introduces a rate of disruption with a dependence on cell concentration higher than one. Such mechanism sums up to other mechanisms, such as turbulence and cavitation, which instead are first order rate phenomena, regulated by the viscosity of the process medium, and were observed in homogenizing valves of different geometries (Diels et al., 2004, 2005a).

Interestingly, the increase of efficiency with cell concentration can be observed only in the high concentration range. Indeed, when cell concentration is excessively reduced, the efficiency of disruption drops to lower levels. This is clear in Figure 2, where the achieved inactivation is reported at increasing the number of passages through the homogenizing valve (steps). 


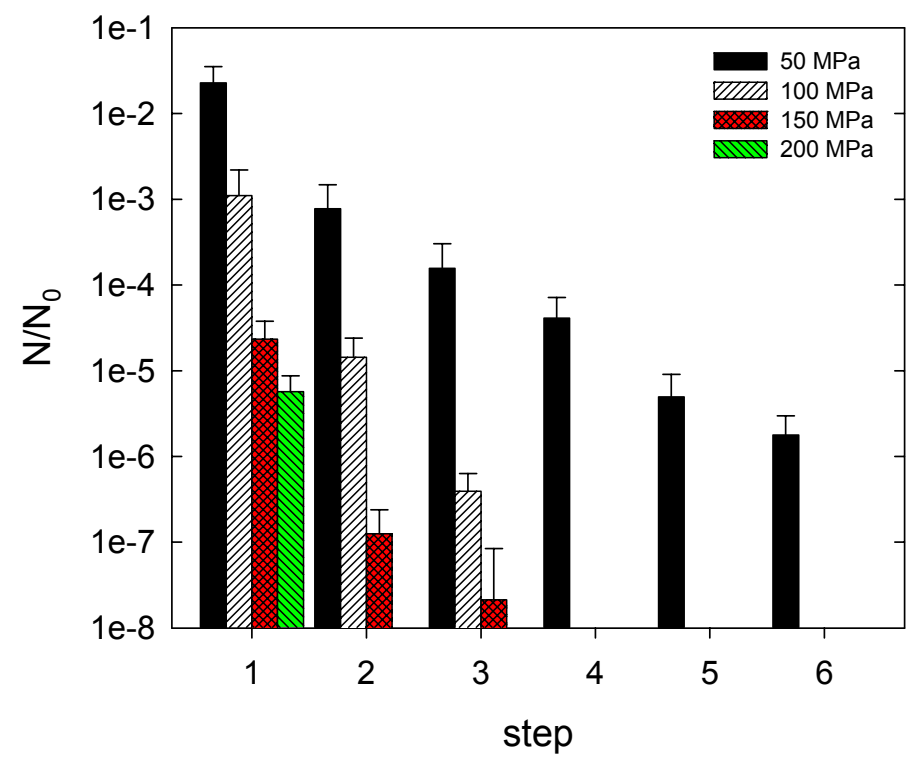

Figure 2. E. coli inactivation upon multistep HPH at pressure levels ranging from 50 to $200 \mathrm{MPa}$ for an initial cell concentration of $10^{7} \mathrm{cfu} / \mathrm{ml}$ and $2{ }^{\circ} \mathrm{C}$ inlet temperature.

Below a certain level of inactivation (4-5 log cycles), the following step accomplishes a lower inactivation than the previous. This is understandable, as the cell concentration is reduced to very low level, and the cell population is selectively composed of cell with higher resistance to the HPH treatment.

Figure 2 shows that at $50 \mathrm{MPa}$ a large number of steps are required for achieving a substantial inactivation: after 6 steps, less than $6 \log$ cycles of reduction are observed. Nevertheless, already at $100 \mathrm{MPa}$, after 4 passages through the homogenizing valve, no detectable cells are left in the process medium, while further increasing the pressure reduces the required steps: 3 steps are needed at $150 \mathrm{MPa}$ and only 2 at $200 \mathrm{MPa}$ for around $8 \log$-cycle inactivation.

Noticeably, in comparison with literature results, the Stansted Power Fluid homogenizer performs better. Figure 3 reports a comparison of the inactivation data of $E$. coli reported in this work with literature data, in terms of decimal reduction pressure $D_{p}$, that is the pressure drop in the homogenizing valve required for achieving a 1 log-cycle inactivation. $D_{p}$ was extrapolated by experimental results at varying pressure, as the inverse of the slope of the logcycle inactivation vs. pressure curve, which generally exhibits a linear behaviour.

$D_{p}$ for the Stansted homogenizer is always lower than for the other homogenisers, even though it must be highlighted that Figure 3 compares data obtained in heterogeneous conditions of cell concentration and inlet temperatures. In particular, most of the literature data were obtained at $25^{\circ} \mathrm{C}$, while ours are obtained at $2{ }^{\circ} \mathrm{C}$, even though, in our apparatus, no experimental evidence was derived of an influence of the inlet temperature on cell inactivation in the $2-30^{\circ} \mathrm{C}$ temperature range.

Inactivation values attained with Niro Soavi (Vannini et al., 2004) and APV Gaulin (Wong et al., 1997) homogenizers are penalized by the low pressure level of operation (130 MPa and $55 \mathrm{MPa}$ respectively). Instead, with the Emulsiflex homogenizer quite different results are reported. Diels et al. (2004 and 2005a) claim a lower $D_{p}$ value than Tahiri et al. (2006) (50 vs $90 \mathrm{MPa}$ ), but however higher than the $D_{p}$ resulting from our data for the same cell concentration $\left(10^{8} \mathrm{cfu} / \mathrm{ml}\right)$. Only upon addition of antimicrobial enzymes and peptides, such as lysozyme or nisin, comparable inactivation efficiency can be attained (Diels et al., 2005b). When switching to a Gram positive bacterium, such as Lactobacillus delbrueckii, with a higher membrane resistance, a significant lower inactivation is achieved. Figure 4 reports the data for a HPH treatment analogous to that performed on E. coli and reported in Figure 2, 
consisting of a multiple passage through the homogenizing valve at a fixed pressure level $(150 \mathrm{MPa}), 2{ }^{\circ} \mathrm{C}$ inlet temperature and $10^{7} \mathrm{cfu} / \mathrm{ml}$ initial concentration. From the data it is evident that only after 5 steps cell inactivation reaches 2 log-cycles, while is negligible after 1 passage and lower than 1 log-cycle after 2 steps.

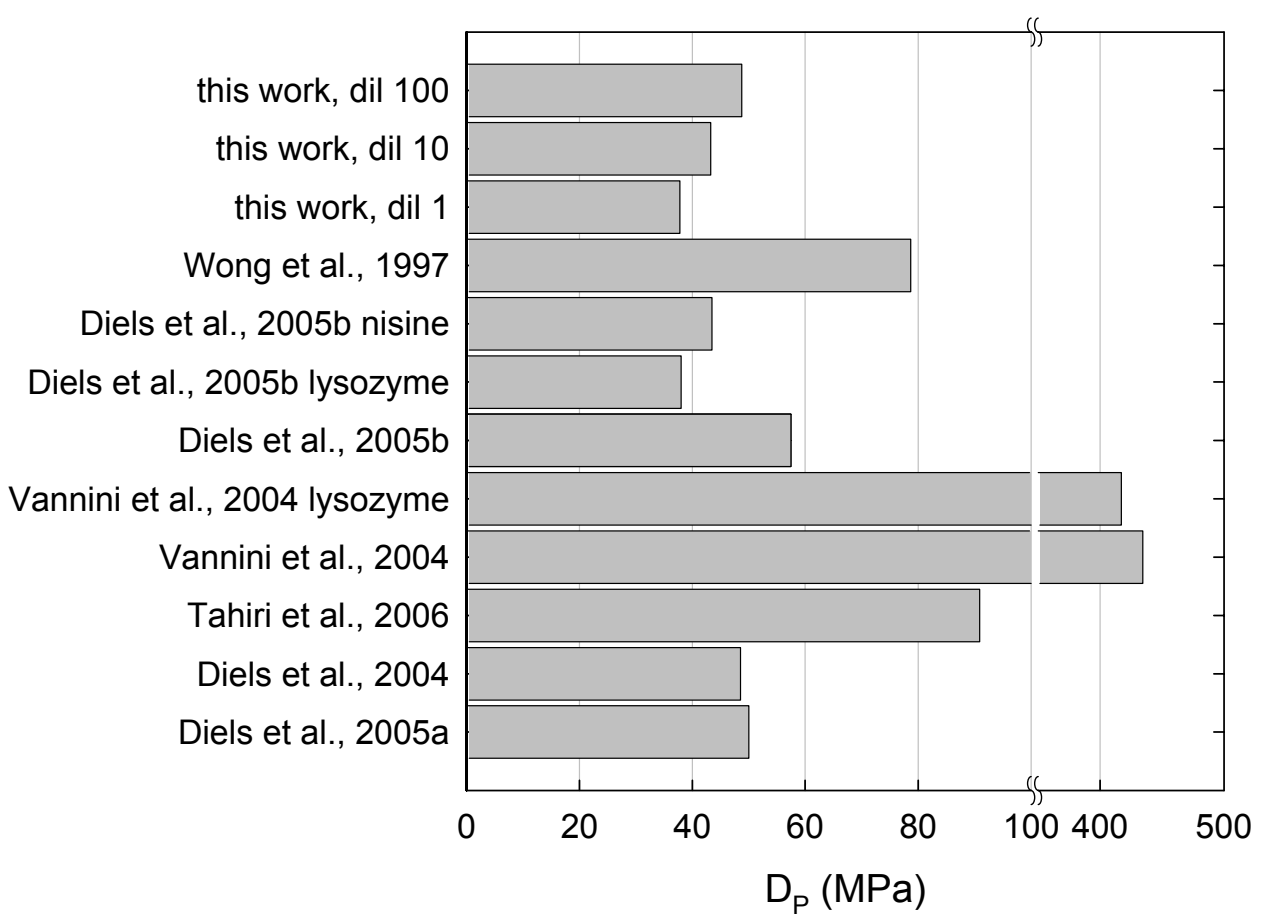

Figure 3. Decimal reduction pressure $(\mathrm{Dp})$ for E. coli: comparison of this work with literature data.

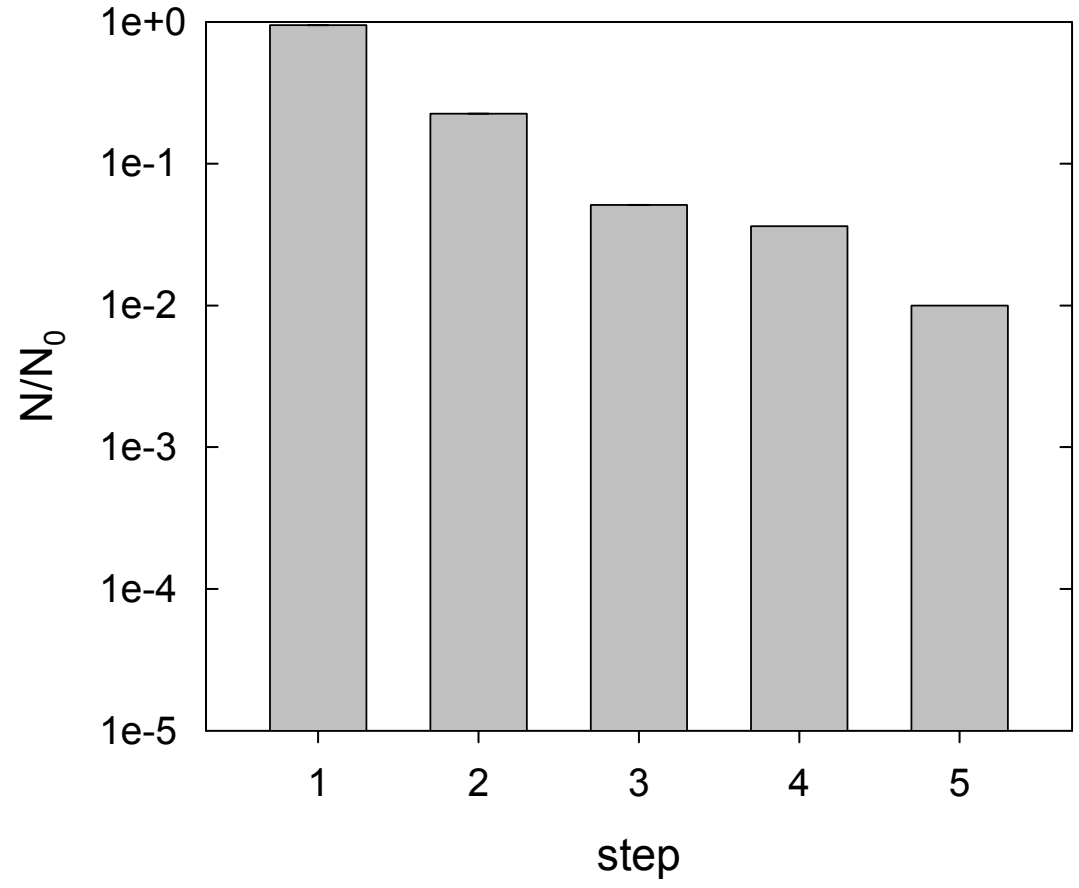

Figure 4. L. delbrueckii inactivation upon multistep $\mathrm{HPH}$ at $150 \mathrm{MPa}$ for an intial cell concentration of $10^{7} \mathrm{cfu} / \mathrm{ml}$ and $2^{\circ} \mathrm{C}$ inlet temperature. 
The significant differences with $E$. coli inactivation can be entirely ascribed to the increased membrane resistance of the Gram-positive strain with respect to the Gram-negative one.

Optical observations unveils that $E$. coli cells, already at the first passage at $150 \mathrm{MPa}$, almost completely disappear, with only small size cells left in the process medium. Such cells, probably due to the reduced size, exhibit a higher resistance to the homogenization treatment, even though, after 2 and 3 passages, are entirely disrupted, leaving only coalescing fragments of cellular material (Figure 5).

In contrast, L. delbrueckii cells are remarkably more resistant to HPH. After the first passage cells of dimensions comparable to the unprocessed ones can be identified, in correspondence to a negligible inactivation. Only after a second passage, smaller cells appear in predominant fraction, even though the level of inactivation is still very low (less than 1 log-cycle). Only at the third passage the first clusters of cell fragments can be observed, in correspondence of 2 log-cycle inactivation.

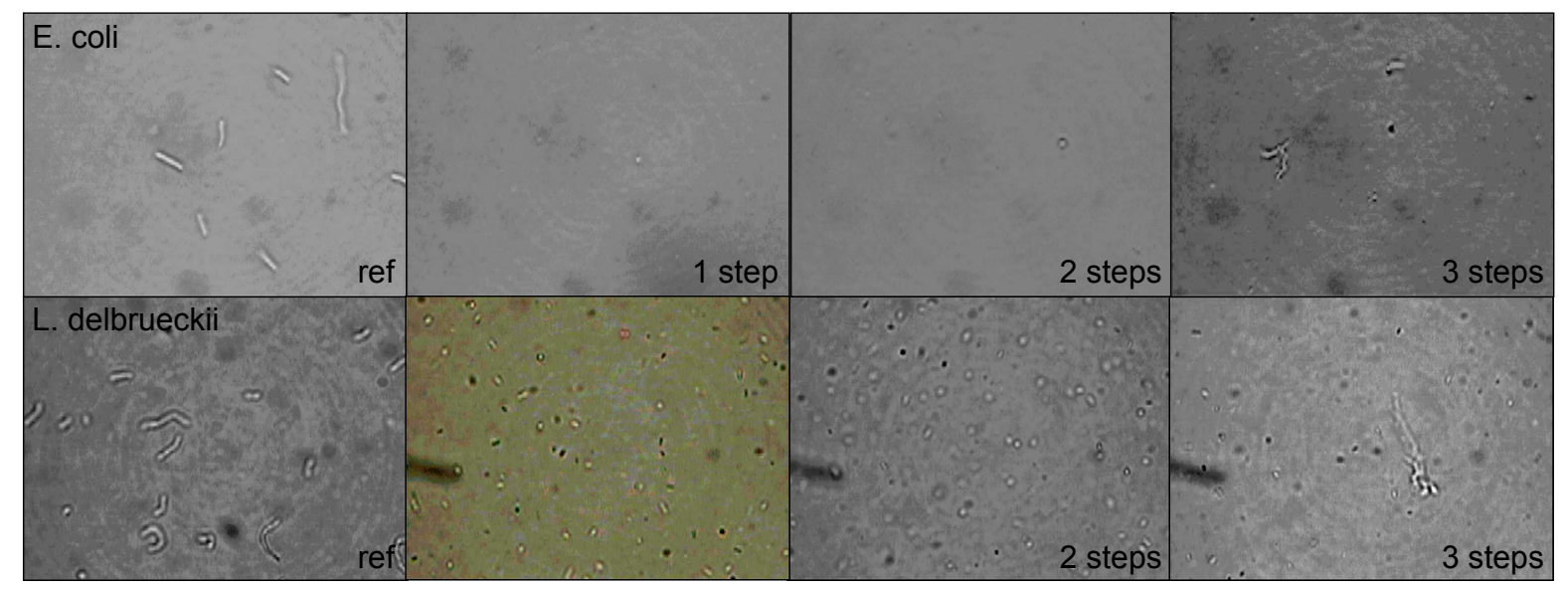

Figure 5. Comparison of the effect of multistep HPH at $150 \mathrm{MPa}$ on E. coli (Figure 2) and $L$. Delbrueckii (Figure 4) with 40x optical microscope.

\section{Shelf-life of Annurca apple juice}

The above reported results suggested that a treatment of three cycles of homogenisation at $150 \mathrm{MPa}$ and ambient temperature could represent a good balance between inactivation efficiency and preservation of the organoleptic properties of the clear Annurca apple juice to be processed.

Sample of clear Annurca apple juice were hence subjected to homogenisation, and unprocessed and homogenised samples were stored for 4 weeks at $4^{\circ} \mathrm{C}$ to evaluate the shelflife through the analysis of total microbial count at fixed storage times $(0,7,14,21,28$ days). Figure 6 shows the number of surviving cell, $N(\mathrm{cfu} / \mathrm{ml})$, of unprocessed and homogenised samples as a function of the storage time. 


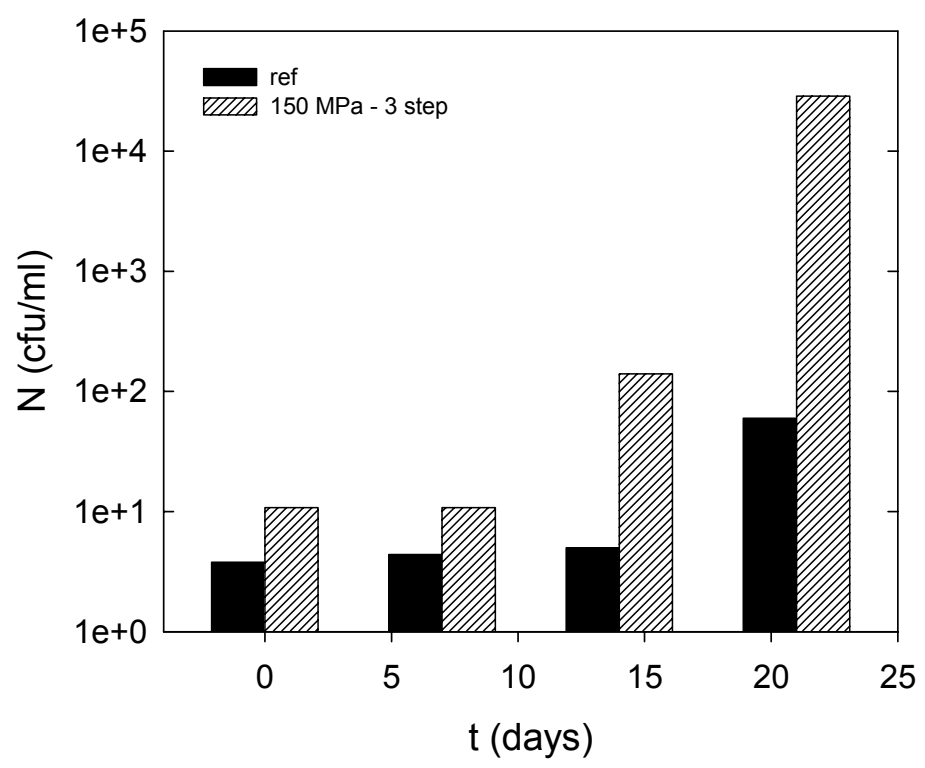

Figure 6. Number of surviving cells of clear Annurca apple juice untreated (ref) and homogenised for 3 cycles at $150 \mathrm{MPa}$ at different storage times at $4{ }^{\circ} \mathrm{C}$.

The total microbial count of unprocessed and homogenised samples follows a different trend. The number of surviving cells in homogenised samples is lower than $10 \mathrm{cfu} / \mathrm{ml}$ for 14 days of storage at $4^{\circ} \mathrm{C}$. In the following days the microbial load increases resulting, however, lower than $100 \mathrm{cfu} / \mathrm{ml}$. Untreated samples, instead, show a significant microbial growth beginning from 7 days of storage. Thus high pressure homogenisation treatment of clear apple juice determines a minimum shelf-life of 14 days at refrigerated conditions. Chemical-physical properties $\left(\mathrm{pH},{ }^{\circ} \mathrm{Brix} \%\right.$, colour, Vitamin $\left.\mathrm{C}\right)$ of untreated and homogenised samples were measured at ambient temperature. The variation of $\mathrm{pH}$ and ${ }^{\circ} \mathrm{Brix} \%$ values are negligible during the storage of unprocessed and processed samples of clear apple juice, as shown in Figure 7.
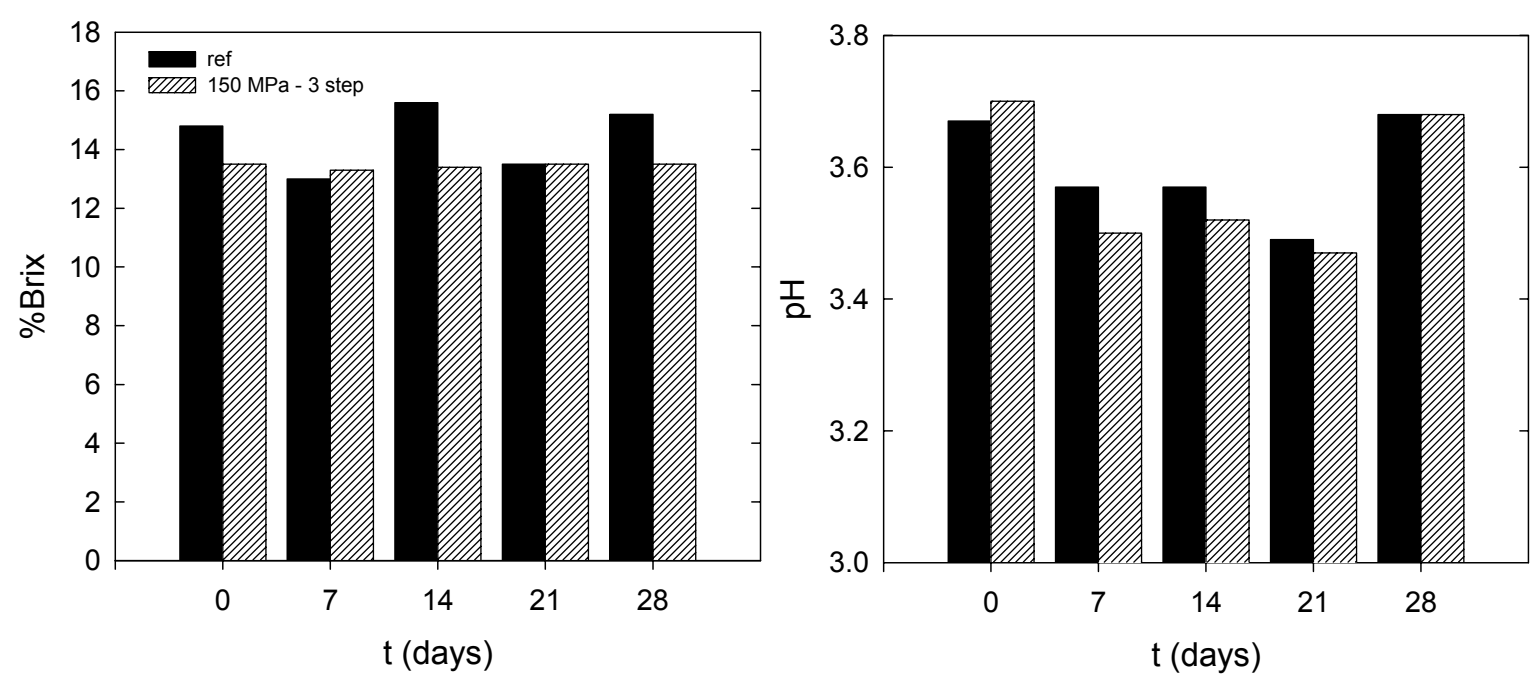

Figure 7. ${ }^{\circ} \mathrm{Brix} \%$ and $\mathrm{pH}$ values of clear Annurca apple juice untreated (ref) and homogenised for 3 cycles at $150 \mathrm{MPa}$ at different storage times at $4{ }^{\circ} \mathrm{C}$.

Similar results are obtained from the measurement of the content of Vitamin $\mathrm{C}$. The peaks corresponding to the detection of Vitamin $\mathrm{C}$ in untreated and homogenised juices are overlapped (data not shown). Therefore the analysed samples show similar content of Vitamin 
C. Hunter scale was used to carry out the colour measurement and the values of $L^{*}, a^{*}, b^{*}$ parameters were evaluated for juice samples. Among the parameters of the Hunter scale, $\mathrm{L}^{*}$, which measures the brightness of the sample, and $\mathrm{a}^{*}$, which indicates the red colour, are relevant to determine the occurrence of the oxidation of the apple juice. The plots of $\mathrm{L}^{*}$ and $\mathrm{a}^{*}$ as a function of storage time for untreated and processed samples are reported in Figure 8.
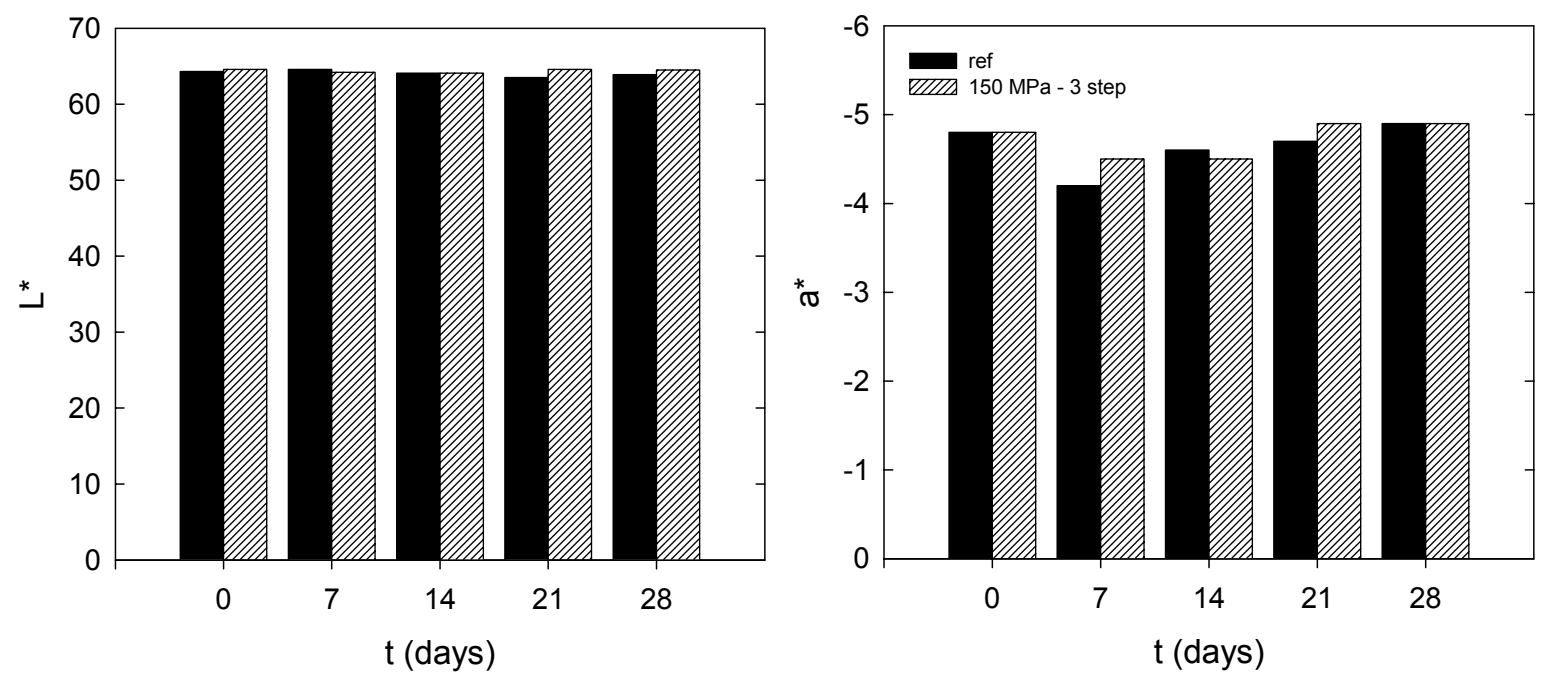

Figure 8. L* and a* values of clear Annurca apple juice untreated (ref) and homogenised for 3 cycles at $150 \mathrm{MPa}$ at different storage times at $4^{\circ} \mathrm{C}$.

High pressure homogenisation does not affect the brightness and the values of the $\mathrm{a}^{*}$ parameter of the apple juice, as shown by the measurement performed immediately after the treatment (storage time $=0$ ). During the storage of the samples in refrigerated conditions the observed variations of colour parameters are negligible and are within the range of the experimental error of the measure. Therefore the colour of the fresh apple juice is preserved by the high pressure homogenisation during the storage in refrigerated condition.

\section{Conclusion}

The objectives of this work were the investigation of the effect on cell inactivation by highpressure homogenisation of the disruption valve geometry and cellular membrane resistance, and the subsequent extension of the results to the application of cold pasteurisation of apple juice.

It was shown that the peculiarity of the homogenizing valve employed in this work (from Stansted Power Fluid) significantly differentiates the results in terms of inactivation level of a model microorganism such as Escherichia coli at the same pressure levels. In particular, a macroscopic difference is observed in the dependence on the cell concentration, which is instead not evident from the results reported in literature (Diels et al., 2004 and 2005a). Hence, in addition to viscosity, which is reckoned as the main external parameter regulating inactivation, it is suggested that in the Stansted homogenizer disruption occurs also due to the interaction of the cells in the valve. This aspect appears to be additive with respect to other mechanisms, such as turbulence and cavitation, claimed as responsible of cell rupture, with the consequence that a higher level of inactivation can be achieved in the Stansted apparatus. Changing the microbial strain to one with stronger membrane resistance, such as Lactobacillus delbueckii, reduces significantly the level of inactivation, with the consequence that higher pressure or a larger number of cycles of homogenization is required.

These considerations suggested to design a treatment of 3 cycles and $150 \mathrm{MPa}$ for processing Annurca apple juice, in order to reduce the microbial load and extend the shelf life of the 
product on one side, and to preserve the quality properties of the juice. The reported results highlight the longer shelf-life of the Annurca apple juice, which is more than doubled with respect to the unprocessed juice, maintaining physical, textural, colour and nutritive properties almost unchanged.

\section{Acknowledgements}

Authors with to acknowledge the Centro di Competenza Produzioni Agroalimentari for the experimental facilities and Mariacarmela Bruno, Ermelinda Lenzi and Beatrice Senatore for assistance with the experimental tests and microbiological analysis.

\section{Literature Cited}

- Clark A.V., Rejimbal T.R., Gomez C.M. (1993). Ultra-high pressure homogenization of unpasteurized juice. US patent, US5232726.

- Diels A.M.J., Callewaert L., Wuytack E.Y., Masschalck B., Michiels C.W. (2005a). Inactivation of Escherichia coli by high-pressure homogenisation is influenced by fluid viscosity but not by water activity and product composition. International Journal of Food Microbiology 101, p. 281.

- Diels A.M.J., De Taeye J., Michiels C.W. (2005b). Sensitisation of Escherichia coli to antibacterial peptides and enzymes by high-pressure homogenisation. International Journal of Food Microbiology 105, pp. 165-175.

- Diels A.M.J., Callewaert L., Wuytack E.Y., Masschalck B., Michiels C.W. (2004). Moderate temperatures affect escherichia coli inactivation by high-pressure homogenization only through fluid viscosity. Biotechnology Progress 20, pp. 1512-1517.

- Diels A.M.J., Wuytack E.Y., Michiels C.W. (2003). Modelling inactivation of Staphylococcus aureus and Yersinia enterocolitica by high-pressure homogenisation at different temperatures. International Journal of Food Microbiology 87, pp. 55-62.

- Feijoo S.C., Hayes W.W., Watson C.E., Martin J.H. (1997). Effects of Microfluidizer® Technology on Bacillus licheniformis Spores in Ice Cream Mix. Journal of Dairy Science 80, pp. 2184-2187.

- Guerzoni M.E., Vannini L., Chaves Lopez C., Lanciotti R., Suzzi G., Gianotti A. (1999). Effect of High Pressure Homogenization on Microbial and Chemico-Physical Characteristics of Goat Cheeses. Journal of Dairy Science 82, pp. 851-862.

- Guerzoni M.E., Vannini L., Lanciotti R., Gardini F. (2002). Optimisation of the formulation and of the technological process of egg-based products for the prevention of Salmonella enteritidis survival and growth. International Journal of Food Microbiology 73, pp. 367-374.

- Kheadr E.E., Vachon J.F., Paquin P., Fliss I. (2002). Effect of dynamic high pressure on microbiological, rheological and microstructural quality of Cheddar cheese. International Dairy Journal 12, pp. 435-446.

- Lanciotti R, Gardini F, Sinigaglia M and Guerzoni M E (1996). Effects of growth conditions on the resistance of some pathogenic and spoilage species to high pressure homogenization. Letters in Applied Microbiology 22, 165-168.

- Lanciotti R, Sinigaglia M, Angelini P and Guerzoni M E (1994) Effects of homogenization pressure on the survival and growth of some food spoilage and pathogenic microorganisms. Letters in Applied Microbiology 18, 319-322.

- Lanciotti R, Vannini L, Patrignani F, Iucci L, Vallicelli M, Ndagijimana M, Elisabetta Guerzoni M. (2006). Effect of high pressure homogenisation of milk on cheese yield and microbiology, lipolysis and proteolysis during ripening of Caciotta cheese. J Dairy Res. online 2006 Feb $14 ;: 1-11$ 
- Lanciotti R., Chaves-López C., Patrignani F., Paparella A., Guerzoni M.E., Serio A., Suzzi G. (2004a). Effects of milk treatment with dynamic high pressure on microbial populations, and lipolytic and proteolytic profiles of Crescenza cheese. International Journal of Dairy Technology 57(1), pp. 19-25.

- Lanciotti R., Tannini L., Pittia P., Guerzoni M.E. (2004b). Suitability of high-dynamicpressure-treated milk for the production of yoghurt. Food Microbiology 21, pp. 753-760.

- Maresca P., Ferrari G., Donsì G. (2006). High pressure homogenisation of fruit juices. In preparation.

- Middelberg A.P.J. (1995). Process-Scale Disruption of Microorganisms. Biotechnology Advances 13(3), pp. 491-551.

- Moroni O., Jean J., Autret J., Fliss I. (2002). Inactivation of lactococcal bacteriophages in liquid media using dynamic high pressure. International Dairy Journal 12, pp. 907-913.

- Paquin P. (1999). Technological properties of high pressure homogenisers: the effect of fat globules, milk proteins, and polysaccharides. International Dairy Journal 9, pp. 329335.

- Popper L., Knorr D. (1990). Applications of high-pressure homogenisation for food preservation. Food Technology 44, p. 84- 89.

- Tahiri I., Makhlouf J., Paquin P., Fliss I. (2006). Inactivation of food spoilage bacteria and Escherichia coli O157:H7 in phosphate buffer and orange juice using dynamic high pressure. Food Research International 39, pp. 98-105.

- Thiebaud M., Dumay E., Picart L., Guiraud J.P., Cheftel J.C. (2003). High-pressure homogenisation of raw bovine milk. Effects on fat globule size distribution and microbial inactivation. International Dairy Journal 13, pp. 427-439.

- Vachon J.F., Kheadr E.E., Giasson J., Paquin P., Fliss I. (2002). Inactivation of some food pathogens in milk using dynamic high pressure. Journal of Food Protection 65, pp. 345-352.

- Vannini L., Lanciotti R., Baldi D., Guerzoni M.E. (2004). Interactions between high pressure homogenization and antimicrobial activity of lysozyme and lactoperoxidase. International Journal of Food Microbiology 94, pp. 123-135.

- Wuytack E.Y., Diels A.M.J., Michiels C.W. (2002). Bacterial inactivation by highpressure homogenisation and high hydrostatic pressure. International Journal of Food Microbiology 77, pp. 205-212.

- Wong H.H., O’Neill B.K., Middelberg A.P.J. (1997). A mathematical model for Escherichia Coli debris size reduction during high pressure homogenisation based on grinding theory. Chem. Eng. Sci. 52(17), pp. 2883-2890. 